\title{
ARTIGO
}

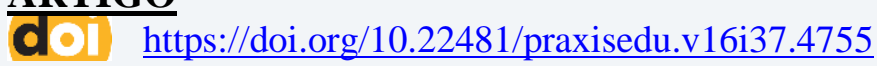

\section{PRÁTICAS CORPORAIS DE AVENTURA NAS DIMENSÕES DO CONTEÚDO: EXPERIÊNCIA NA EDUCAÇÃO FÍSICA INFANTIL}

\author{
CONTENT DIMENSIONS OF ADVENTURE CORPORAL PRACTICES: EXPERIENCE \\ IN CHILDREN'S PHYSICAL EDUCATION
}

\author{
PRÁCTICAS CORPORALES DE AVENTURA EN LAS DIMENSIONES DEL \\ CONTENIDO: EXPERIENCIA EN LA EDUCACIÓN FÍSICA INFANTIL
}

Filipe Botelho Francisco

Universidade do Estado de Santa Catarina - Brasil

Juliana de Paula Figueiredo

Universidade do Estado de Santa Catarina - Brasil

Viviane Preichardt Duek

Universidade do Estado de Santa Catarina - Brasil

Resumo: O relato descreve uma experiência com as práticas corporais de aventura nas aulas de Educação Física Infantil, pautada nas dimensões dos conteúdos. As intervenções foram desenvolvidas com crianças de cinco a seis anos, em uma instituição de Educação Infantil da rede pública municipal de Florianópolis/SC. As modalidades tematizadas nas aulas foram: parkour, técnicas verticais (rapel e escalada) e atividades com pranchas (surfe e skate). A experiência indicou que as práticas corporais de aventura representam um conteúdo inovador nas aulas de Educação Física, despertando nas crianças o desejo de conhecer e praticar outras modalidades. Concluímos que é possível inserir as práticas corporais de aventura, explorando temas relacionados às dimensões conceitual, atitudinal e procedimental dos conteúdos, desde a Educação Infantil.

Palavras chave: Educação física; Educação infantil; Práticas corporais de aventura.

\begin{abstract}
This report describes an experience with adventure corporal practices in the classes of children's Physical Education, based on the dimensions of the contents. The interventions were carried out with children from five to six years old, in a public school of Florianópolis/SC. The modalities addressed in the classes were: parkour, vertical techniques (abseiling and climbing) and board activities (surfing and skateboarding). The experience has indicated that adventure corporal practices represent an innovative content in Physical Education classes, awakening in the children the desire to know and to practice other modalities. We conclude that it is possible to insert the adventure corporal practices, exploring subjects related to the conceptual, attitudinal and procedural content dimensions since children's Education.
\end{abstract}

Keywords: Physical education. Children's education. Adventure corporal practices. 
Resumen: Este informe describe una experiencia con prácticas corporales de aventura en las clases de Educación Física para niños, con base en las dimensiones de los contenidos. Las intervenciones se llevaron a cabo con niños de cinco a seis años, en una escuela pública de Florianópolis/SC. Las modalidades abordadas en las clases fueron: parkour, técnicas verticales (rappel y escalada) y actividades de tabla (surf y skateboard). La experiencia ha indicado que las prácticas corporales de aventura representan un contenido innovador en las clases de Educación Física, despertando en los niños el deseo de conocer y practicar otras modalidades. Concluimos que es posible insertar las prácticas corporales de aventura, explorando temas relacionados a las dimensiones conceptual, actitudinal y procedimental, de los contenidos, desde la Educación Infantil.

Palabras clave: Educación física. Educación infantil. Prácticas corporales de aventura.

\section{Introdução}

As práticas corporais de aventura ${ }^{1}$ compreendem um conjunto de atividades como surfe, skate, stand up paddle, slackline, paraquedismo, parkour, escalada, trilha, entre outros, que têm se tornado uma constante na atualidade. Trata-se, portanto, de modalidades que tem como características intrínsecas a aventura, o risco e as emoções, as quais representam fator motivacional para os praticantes. Assim, essas práticas apresentam especificidades relacionadas com a segurança, o controle dos riscos e os desafios, de modo que a sua inclusão no ambiente escolar seja possível (PAIXÃO, 2017; FRANCO; CAVASANI; DARIDO, 2014).

No tocante à Educação Física escolar, os autores supracitados argumentam que, para além dos conteúdos tradicionalmente abordados nas aulas, os estudantes têm o direito de vivenciar outras situações que fazem parte da cultura corporal, ampliando, assim, seus conhecimentos, experiências e oportunidades de escolhas. Logo, a inserção de novos conteúdos no ambiente escolar implica a superação de barreiras ao longo do tempo, como a tradição das práticas esportivas, que se mostra hegemônica. Nesse contexto, as práticas corporais de aventura promovem a inovação perante os esportes tradicionais, constituindo-se um campo de intervenção profissional instigante e com potencial para ser desenvolvido em diferentes contextos de ensino e aprendizagem, dentre eles o escolar (PAIXÃO, 2017).

Diante desses fatores, observa-se uma crescente inserção dessas práticas na Educação Física Escolar. Trabalhos realizados por Pimentel et al. (2017), Franco (2008), Tahara e Darido

\footnotetext{
${ }^{1}$ Neste trabalhado adotou-se o termo práticas corporais de aventura. Contudo, não há consenso na literatura sobre a terminologia específica, utilizando-se termos diversos e complementares entre si, tais como: atividades de aventura (MARINHO, 2013); esportes radicais, de ação e de aventura (PEREIRA; ARMBRUST, 2009); esportes radicais (UVINHA, 2001).
} 
(2016) confirmam a relevância e os benefícios desse conteúdo ao ser abordado no âmbito da escola. Ampliando essa discussão, Inácio et al. (2016) propõem uma reflexão acerca da inserção das práticas corporais de aventura na Base Nacional Comum Curricular (BNCC), a qual sugere o desenvolvimento desse conteúdo a partir dos anos finais do Ensino Fundamental, sendo que, na visão destes autores, estas práticas deveriam ser exploradas desde a Educação Infantil, posição da qual compartilhamos. Embora insipientes, experiências bem-sucedidas com esse nível de ensino já vêm sendo desenvolvidas, confirmando a possibilidade de se trabalhar as práticas corporais de aventura com crianças menores, adaptando espaços e materiais, além de explorar o imaginário e o jogo simbólico de modo a adequar essas vivências às características do público da Educação Infantil (MARTINS; ANSELMO, 2015; ESPINOZA, 2009; COSTA NETO; SANTOS; EDNEY, 2008).

Além desses aspectos, evidencia-se o potencial educativo das práticas corporais de aventura, uma vez que estas permitem abordar temas que envolvem as dimensões conceitual, procedimental e atitudinal dos conhecimentos. Estas, por sua vez, abarcam o "saber" e/ou o “conhecer" (dimensão conceitual), o "saber fazer" (dimensão procedimental), e o "saber ser" (dimensão atitudinal) (PAIXÃO, 2017; SOUZA; SILVA, 2013; PEREIRA; ARMBRUST, 2010; DARIDO, 2005).

Pereira e Armbrust (2010) descrevem que na dimensão conceitual estão presentes os aspectos históricos das modalidades, os locais de prática, os equipamentos, os objetivos e motivos para a prática, além da compreensão do fator risco intrínseco às diferentes modalidades. No tocante à dimensão procedimental, podem ser realizadas as técnicas de movimentos, as técnicas e princípios de segurança, os processos pedagógicos e as adaptações necessárias dessas práticas corporais para cada faixa etária e condições do contexto escolar. Por fim, a partir da dimensão atitudinal, podem ser desenvolvidas noções de regras, ética, respeito às questões de segurança, gestão do risco, além das relações de cooperação, liderança, confiança e superação de limites presentes no decorrer da prática de uma dada modalidade.

Frente ao exposto, o presente relato objetiva descrever uma experiência com as práticas corporais de aventura nas aulas de Educação Física Infantil a partir da dimensão conceitual, procedimental e atitudinal dos conteúdos. Trata-se de uma experiência desenvolvida no contexto do Estágio Curricular Supervisionado $\mathrm{I}^{2}$, no curso de Licenciatura em Educação Física

\footnotetext{
2 O referido estágio é realizado no quinto semestre do curso de Licenciatura em Educação Física do CEFIDUDESC, sempre em instituições públicas de Educação Infantil em que os acadêmicos/estagiários são acompanhados pelo professor da disciplina, bem como pelo professor de Educação Física da instituição campo de estágio.
} 
do Centro de Ciências da Saúde e do Esporte, da Universidade do Estado de Santa Catarina, com um grupo de crianças de cinco a seis anos, em uma instituição de Educação Infantil pública, pertencente à rede municipal de Florianópolis, Santa Catarina, Brasil.

\section{Situando o contexto da experiência e seus atores}

A experiência de ensino aqui relatada foi desenvolvida em um Núcleo de Educação Infantil Municipal (NEIM), na cidade de Florianópolis (SC), que atende crianças de dois a cinco anos, nos períodos matutino e vespertino, organizadas em oito grupos ${ }^{3}$, quatro por período. $\mathrm{Na}$ referida instituição, trabalham professoras regentes, auxiliares de sala ${ }^{4}$, diretora, coordenadora pedagógica, professora de Educação Física/Supervisora de estágio, além de funcionárias responsáveis pelo serviço administrativo de limpeza e alimentação.

Quanto ao espaço físico, na parte externa encontra-se um parque com brinquedos variados (balanços, gira-gira, escorregadores, casa de boneca, casa na árvore, trepa-trepa, túnel e torre de pneus, playground estilo barco, gangorra, dentre outros), uma quadra de concreto, além de área arborizada com bancos e mesas. Na parte interna existe uma pequena biblioteca, quatro salas de aula, sala de direção e coordenação, sala dos professores, cozinha, lavanderia, banheiro unissex adaptado e um hall de entrada amplo (com uma pequena brinquedoteca e recursos audiovisuais). Entre os materiais disponíveis para as aulas de Educação Física, encontramos bolas de tênis, bolas de borracha, bolas de plástico, cordas, arcos, chinelão, túnel de tecido, colchonetes, pneus, raquetes de frescobol, boca do palhaço, dentre outros.

Nas salas de aula há brinquedos diversos, de cores, formas, texturas e tamanhos variados, de maneira acessível às crianças, organizados em estantes. Há materiais para pintar, colorir, recortar e colar, além de mesas, cadeiras e um banheiro adaptado à estatura das crianças. As salas são organizadas na forma de cantos temáticos (cantinho de brinquedos, livros, etc.). Também há um tapete com almofadas onde as professoras se reúnem com as crianças para conversar, cantar, contar histórias, etc. Como não há refeitório na instituição, as crianças fazem as refeições na sala.

\footnotetext{
${ }^{3}$ Os grupos são organizados de acordo com a idade das crianças. O número de crianças por grupo varia conforme a faixa etária, de modo que grupos com crianças menores têm um número reduzido de crianças, enquanto grupos com faixa etária maior podem apresentar até 25 crianças. Não há atendimento em período integral na referida instituição.

${ }^{4}$ Cada grupo conta com uma professora regente e uma auxiliar. Quando há, no grupo, crianças com deficiência, há mais uma professora auxiliar para atendê-la.
} 
O grupo com o qual trabalhamos era composto por 25 crianças - doze meninos e treze meninas - com idade aproximada de cinco anos e meio. Era um grupo que se mostrava bastante curioso, ativo e receptivo a novas propostas, com boa interação entre as crianças e entre estas e os professores. As aulas de Educação Física aconteciam duas vezes por semana, com duração de uma hora e quinze minutos cada aula ${ }^{5}$, o que corresponde às três aulas semanais de 45 minutos cada uma, durante um período de 10 semanas.

Passado o período de observação, percebemos que as crianças apresentavam um bom desempenho motor, explorando diferentes espaços e materiais presentes na instituição, tanto nas aulas de Educação Física propostas pela supervisora do estágio, como nos momentos de parque. Percebemos que elas subiam e desciam com agilidade dos bancos, árvores e brinquedos do parque. Por sua vez, nas aulas de Educação Física, mostravam interesse pelas atividades que envolviam movimentos mais amplos como jogos e brincadeiras de pega-pega, por exemplo. Também eram desenvolvidos junto às crianças conteúdos relacionados às danças folclóricas e à capoeira.

Considerando as características observadas nas crianças, bem como os conteúdos desenvolvidos pela professora supervisora, no momento do planejamento das intervenções cogitamos a possibilidade de abordar as práticas corporais de aventura, mediante a compreensão de que se trata de um conteúdo ainda pouco explorado no contexto da Educação Infantil, além de compreender um interesse pessoal do estagiário em tematizar esse conteúdo nas aulas de Educação Física na Educação Infantil. De modo específico, organizamos uma proposta de ensino visando as três dimensões do conteúdo (procedimental, conceitual e atitudinal) (ZABALA, 1998), numa tentativa de romper com a ideia que perpassa o ensino dos conteúdos nas aulas de Educação Física e que privilegiam a dimensão procedimental dos conteúdos, não abrangendo as demais dimensões (BARROSO; DARIDO, 2009; DARIDO, 2005).

Todo o processo foi registrado por meio de fotos, filmagens e desenhos produzidos pelas crianças e que serviram de subsídio para a elaboração do presente relato. Além disso, o relato a seguir encontra-se embasado em documentos produzidos na disciplina de Estágio, tais como plano de trabalho e planos de aula, registros pedagógicos semanais, bem como relatório final. Destaca-se que por se tratar de um relato de experiência, desenvolvido em uma instituição pública, pressupõe-se, para este, a ausência de rigor sistemático requerido em pesquisas. Todavia, enfatiza-se que, tanto ao longo da experiência quanto na redação deste relato, os

\footnotetext{
${ }^{5}$ Destaca-se o fato de que uma das aulas ministradas acontecia durante a rotina de alimentação das crianças, de modo que era necessário ajustar o planejamento neste dia, devido ao tempo de aula ser reduzido.
} 
princípios éticos foram adotados. Ademais, no ato da matrícula anual, os pais e/ou mães e/ou responsáveis assinam um termo, permitindo, para fins acadêmicos, o registro das atividades realizadas.

\section{Práticas Corporais de Aventura nas três dimensões do conteúdo: refletindo sobre as experiências}

A abordagem dos conteúdos nas aulas obedeceu à seguinte dinâmica: em um primeiro momento, ainda em sala, o conteúdo era abordado por meio de um breve questionamento feito às crianças, com o apoio de vídeos e/ou imagens sobre a modalidade que seria vivenciada naquela aula. Em um segundo momento, utilizando os diversos materiais e espaços da instituição, eram realizadas atividades que remetiam aos movimentos de cada modalidade, as quais tiveram adaptações, a fim de possibilitar a participação efetiva das crianças. No terceiro momento era realizada uma conversa final com as crianças sobre as atividades realizadas (qual foi a modalidade que aprendemos hoje; houve risco; alguém se machucou; o que sentiram; etc.).

As práticas corporais de aventura tematizadas nas aulas foram: parkour, técnicas verticais (rapel e escalada), atividades com pranchas (surfe e skate), abrangendo tanto o conhecimento sobre as práticas corporais de aventura, histórico e conceitos, como a vivência dos elementos de cada modalidade e a construção de valores e atitudes. Portanto, foram abordados temas referentes à segurança, questões éticas e de consciência ambiental, além de atitudes de respeito e colaboração nas práticas das atividades.

\subsection{Parkour}

O Parkour é considerado uma atividade de aventura que tem por objetivo transpor obstáculos naturais ou não, com a maior eficiência possível, saindo de um ponto para outro com segurança, superando os obstáculos do caminho (PERREIRA; ARMBRUST, 2010). Assim, o simples fato de pular um muro ou brincar de pega-pega, pode ser considerada uma atividade relacionada ao parkour.

Em nossas intervenções, visando contemplar a dimensão conceitual desta prática corporal, organizamos uma roda inicial com o intuito de levantar os conhecimentos prévios das crianças sobre o tema da aula: Alguém sabe o que é parkour? Alguém já praticou o parkour? Vocês já viram alguém praticando o parkour? Chamou a atenção o desconhecimento das 
crianças sobre este conteúdo. Na sequência, foram apresentados alguns vídeos de crianças e adultos praticando o parkour, realizando manobras perfeitas e outras que não terminavam bem, a fim de descontrair e alertar sobre os acidentes que podem ocorrer se não seguirem as instruções de segurança. Esse momento foi importante para um primeiro contato das crianças com a modalidade, bem como para despertar o interesse para esta prática nas aulas de Educação Física Infantil. Tais aspectos foram evidenciados nos estudos de Franco (2008) e Paixão (2017), ao destacarem a relevância da roda inicial e da exploração de recursos midiáticos para a introdução das práticas corporais de aventura no contexto escolar.

A dimensão procedimental dos conteúdos pode ser visualizada nas atividades de iniciação desta prática corporal de aventura onde adotou-se uma abordagem lúdica, com a exploração dos diversos espaços (sala de aula, hall, quadra e parque) e materiais (cadeiras, bancos, mesas, pneus, cordas, dentre outros) presentes na instituição. Paixão (2017) afirma que essa dimensão visa explorar as vivências no decorrer das aulas, indo das ações mais simples, possíveis de serem realizadas em qualquer ambiente escolar, até aquelas mais específicas que requerem o uso de equipamentos, conhecimentos e habilidades próprios da modalidade tematizada.

Desta forma, as atividades propostas no contexto das aulas de Educação Física Infantil preconizaram a vivência, de modo adaptado, dos saltos, da transposição de obstáculos, equilíbrio e rolamentos, enquanto fundamentos do parkour. O desenvolvimento das aulas pautou-se na progressão dos conteúdos, com a implementação de níveis de dificuldade. Em cada aula, era preocupação do estagiário organizar situações pedagógicas em que as crianças pudessem explorar os materiais de acordo com as suas habilidades e criatividade, havendo, em seguida, um maior direcionamento por parte do estagiário que conduzia as crianças à realização de determinados movimentos. Para exemplificar esse aspecto cita-se a aula sobre saltos e transposição de obstáculos em que foram utilizados bancos, mesas e cadeiras, em que as crianças, em um primeiro momento, puderam explorar livremente estes materiais, transpondoos da maneira desejada. Após essa experimentação, o estagiário propôs um movimento específico do parkour, o qual consiste em saltar sobre o banco apoiando uma mão em cada lateral, sem que solte nenhuma das mãos até a finalização da manobra.

Vale destacar, ainda, a utilização de outros ambientes da instituição, comumente, pouco explorados nas aulas de Educação Física, a exemplo do parquinho que também foi incorporado em nossas intervenções de maneira transversal, ou seja, em todas as aulas houve preocupação em usar este espaço na realização do que era proposto, como subir os pneus, descer no 
escorrega, correr na ponte, desviar dos balanços, atravessarem o parque sem tocar em nada, subir e descer nos brinquedos, assim, utilizando diferentes estratégias lúdicas e o espaço grande do parque para realizar as práticas de aventura. Um exemplo era a realização de movimentos simples, iniciando com atividade em um brinquedo específico, como a gangorra, até que todos os locais do parque fossem explorados, ressignificando, assim, a utilização desse espaço nas aulas de Educação Física.

Outro local explorado para a realização das atividades foi o próprio ambiente da sala de aula, em que o estagiário organizou diferentes situações com os materiais disponíveis, tais como cadeiras, mesas, tapetes, almofadas e colchões, a fim de estimular as crianças a saltarem e transporem obstáculos, envolvendo diferentes alturas e níveis de dificuldade. Destaca-se, assim, a importância da mediação feita pelo estagiário ao longo das atividades propostas, a qual favoreceu a evolução nos comportamentos das crianças que se tornaram mais confiantes e autônomas para a realização dos movimentos. Como exemplo, podemos citar a progressão de um exercício em que era proposto às crianças saltarem de uma cadeira e depois de uma mesa. Inicialmente, algumas crianças precisaram da ajuda do estagiário para subirem na mesa e realizarem o salto sobre o colchão. Na sequência, foi retirado o colchão e as crianças deveriam saltar diretamente da mesa em direção ao chão, em um primeiro momento com a ajuda e num segundo momento sem a ajuda do estagiário.

Por sua vez, a dimensão atitudinal do conteúdo apresenta-se intimamente relacionada às dimensões conceitual e procedimental. Aqui o estagiário buscou chamar a atenção das crianças para as questões de segurança e regras. Um exemplo disso seria em relação às questões de segurança, se apresenta algum risco ao seu estado físico, sobre os materiais utilizados, o local onde é realizado sendo seguro ou não, lugares abertos (pracinhas, parques) e fechados (construções, ginásios), o respeito com os colegas durante a execução dos movimentos sozinhos ou com ajuda do estagiário, saber que os movimentos mais difíceis devem ser acompanhados de um adulto experiente na modalidade observando e auxiliando durante a realização dos mesmos.

Com o intuito de aumentar o nível de segurança nas aulas, foram apresentados, em analogia a um semáforo, cartões verde (seguro), amarelo (cuidado) e vermelho (arriscado ou perigoso). Quando era mostrado algum destes cartões, as crianças já identificavam se estavam fazendo corretamente ou incorretamente, com segurança ou em situação arriscada. Os cartões também eram mostrados na conversa final com outro significado: o vermelho representando quem havia se machucado durante as atividades ou não se comportado durante a aula e o verde 
representava quem havia realizado todas as atividades sem se machucar e apresentado bom comportamento. Esse elemento tornou as vivências mais seguras e se apresentou como um ótimo recurso para o desenvolvimento das práticas corporais de aventura e gestão da segurança com as crianças, além de contribuir para a autonomia das mesmas, que aprenderam, ao longo das intervenções, sobre os cuidados básicos na execução das modalidades vivenciadas.

\subsection{Técnicas verticais (escalada e rapel)}

O conhecimento acerca das técnicas verticais - escalada e rapel - pode ser considerado um conteúdo inovador a ser trabalhado nas escolas (PEREIRA; CARCERONI, 2005), podendo ser inserido já na Educação Infantil uma vez que ainda se trata de um conteúdo pouco difundido no ambiente educacional, cabendo ao professor de Educação Física proporcionar às crianças e jovens a aproximação com tais práticas.

Partindo de tais pressupostos, para a abordagem da dimensão conceitual da escalada e do rapel, organizamos uma roda inicial com o intuito de levantar os conhecimentos e experiências anteriores das crianças sobre o tema da aula. Para subsidiar esse momento, utilizamos vídeos que remetiam às práticas verticais realizadas por adultos e crianças em diferentes ambientes, além de alguns tipos de acidentes que podem ocorrer se não seguirem as instruções. Feito isso, lançamos alguns questionamentos, tais como: $O$ que vimos no vídeo? $O$ que estão fazendo? Alguém sabe o nome destas atividades? Alguém já praticou escalada ou rapel? Já viram alguém praticando? Ao longo dos diálogos, as crianças fizeram relação entre a prática do rapel e da escalada com os movimentos realizados pelo homem aranha, personagem em quadrinhos. Essa conversa inicial auxiliou na identificação e compreensão acerca dos equipamentos, ambientes e movimentos presentes nessas práticas (PAIXÃO, 2017), além de despertar o interesse em realizar tais atividades nas aulas de Educação Física.

A dimensão procedimental desse conteúdo é evidenciada nas atividades de iniciação desta prática corporal de aventura, onde adotou-se uma abordagem lúdica com a exploração dos diversos espaços (sala de aula, hall, quadra e parquinho) e materiais (cadeiras, bancos, mesas, pneus, cordas, dentre outros), presentes na instituição de modo a favorecer a aprendizagem de movimentos presentes na escalada e no rapel, os quais envolvem o subir, descer e trepar e que fazem parte do repertório motor das crianças da Educação Infantil (PEREIRA; ARMBRUST, 2010). 
Para a vivência destas práticas corporais buscamos adequar os espaços da instituição que permitissem simular os movimentos realizados em ambas as modalidades. $\mathrm{O}$ elemento lúdico ficou por conta da imitação de movimentos de animais (saltar como sapo, canguru, andar em quatro apoios como leão) ou super-heróis (homem aranha, homem formiga), os quais fazem parte do imaginário infantil. Assim, com pneus dispostos na quadra que representavam uma parede de escalada, as crianças eram estimuladas a deslocarem-se em quatro apoios, simulando os movimentos básicos desta modalidade. O muro, por sua vez, transformou-se em uma "montanha" que as crianças deveriam escalar/descer. Para esta atividade, duas cordas, distantes entre si, foram amarradas no alto do muro, de modo que as crianças deveriam subir/escalar o muro com o auxílio de uma das cordas, depois percorrer um trajeto em que escalavam lateralmente com os pés apoiados na base do muro e as mãos segurando na grade e, por fim, havia outra corda onde era realizado o rapel com as técnicas de salto para trás, finalizando o circuito. As crianças foram acompanhadas pelo estagiário, a fim de garantir a segurança na execução dos movimentos o que, na visão de Souza e Silva (2013), é essencial na prática da escalada, por se tratar de uma atividade que envolve certo risco, o medo e os desafios que precisam ser controlados a fim de possibilitar a sua introdução no contexto escolar.

$\mathrm{Na}$ dimensão atitudinal, além das questões de segurança e regras exploradas por meio da estratégia de cartões coloridos, a vivência da escalada e do rapel enfatizou o risco, o medo de altura, autoconfiança, timidez e/ou vergonha explicitados pelas crianças ao realizarem os movimentos, bem como contribuiu para a formação de valores como o respeito aos próprios limites e dos colegas, a partir do entendimento de que em movimentos que envolvem maior risco deve-se ter um adulto observando e auxiliando durante a sua realização.

\subsection{Atividades com prancha: surfe e skate}

O surfe e o skate são modalidades complementares entre si, devido características semelhantes, o que torna interessante a abordagem conjunta, como foi o caso da proposta aqui relatada. De acordo com Souza (2013), a aprendizagem dos fundamentos iniciais do surfe podem ocorrer em locais controlados, fechados e estáveis, de modo que haja uma construção e transferência do aprendizado, até concretizar o ato de surfar. Por sua vez, Pereira e Armbrust (2010) afirmam que os conhecimentos adquiridos por uma prática corporal de aventura na água, neste caso o surfe, podem contribuir para as vivências motoras em outro ambiente. No que se refere ao skate, Armbrust (2013) aponta que este começou a se difundir no Brasil justamente 
por praticantes de surfe, devido a anúncios que continham em uma revista específica desta modalidade, sendo chamado, inclusive, de "surfinho".

Para desenvolver este último conteúdo, buscamos conduzir nossas intervenções visando contemplar a dimensão conceitual destas duas práticas corporais da mesma forma que nos outros temas anteriormente trabalhados, organizando uma roda inicial no sentido de levantar os conhecimentos prévios referentes às modalidades surfe e skate, indagando às crianças: Alguém sabe o que é surfe? E o que é skate? Alguém já praticou o surfe ou skate? Vocês já viram alguém praticando o surfe ou skate? Há movimentos parecidos no surfe e no skate? Quais são esses movimentos? Em que locais eles são praticados? Quais materiais são usados para sua segurança? O fato de morar em uma ilha tornou mais fácil o conhecimento destas modalidades para as crianças, por ser comum a visualização de praticantes nas praias, parques, beira-mar, entre outros locais. Contudo, o desconhecimento ainda existia com relação a estas práticas corporais, especialmente sobre os equipamentos de segurança e à maneira de realizar.

Para promover a aproximação com a realidade, bem como alertar sobre os acidentes que podem ocorrer se não utilizarem os equipamentos adequados, foram expostos vídeos de crianças e adultos praticando o surfe e o skate. Também fez-se um breve alerta sobre aspectos relacionados ao meio ambiente e à poluição, os quais estão intimamente ligados a essas práticas (PAIXÃO, 2017; MARINHO; INÁCIO, 2007). Segundo Costa Neto, Santos e Edney (2008), as práticas corporais de aventura podem ser realizadas em diferentes ambientes de forma lúdica e criativa, com isso as diversas modalidades podem se tornar um meio para trabalhar habilidades e capacidades específicas e o desenvolvimento da motricidade na infância, além de valores, como os relacionados ao contexto do lazer e aos aspectos ambientais.

No que se refere à dimensão procedimental para trabalhar as modalidades com prancha, o desenvolvimento das aulas pautou-se na progressão dos conteúdos, com a implementação de níveis de dificuldade e adotou-se uma abordagem lúdica, como contos de histórias do mar e caça ao tubarão. Com isso, as atividades propostas no contexto das aulas de Educação Física Infantil preconizaram a vivência, de modo adaptado, da coordenação de membros superiores na remada e apoio na prancha, coordenação dos membros inferiores para ganhar aceleração no skate e de equilíbrio das diferentes posições na vertical e horizontal, enquanto fundamentos semelhantes entre o surfe e o skate.

Para ampliar o equilíbrio, sendo esta uma capacidade crucial nas modalidades com prancha, as crianças foram estimuladas a realizar um percurso que previa o deslocamento da sala de aula até o local onde as demais atividades seriam desenvolvidas. Sendo assim, deveriam 
caminhar livremente sobre uma corda estendida no chão e bancos espalhados, pois seria visualizada a forma que iriam passar se equilibrando sobre os materiais. Após passarem livremente, o estagiário estimulou que passassem imitando um caranguejo (deslocamento lateral), aproximando-se, assim, da posição utilizada para surfar e andar de skate; por fim, caminhar sobre o slackline, sendo este utilizado para chegar a um desequilíbrio semelhante às modalidades com prancha, exigindo uma capacidade de equilíbrio maior quando este se faz lateralmente.

A fim de proporcionar a vivência dos movimentos do surfe, foi explorado o espaço do hall como outra opção possível para as aulas de Educação Física. Foi vivenciada uma brincadeira onde as crianças deveriam fugir do tubarão: o tubarão (estagiário) deveria pegar os nadadores (crianças) antes que eles chegassem à praia, representada por bancos no outro lado; o tubarão deveria pegar os nadadores que estavam surfando ou nadando e, com isso, as crianças deveriam realizar a "braçada do gigante" (nado crawl) ou imitar um caranguejo para deslocarse (onde teriam que realizar deslocamento lateral, semelhante à posição do surfe), para chegar à praia e se salvar. Também foi realizada uma atividade de simulação de surfe na qual a prancha era representada pelo banco e a onda era representada pela parede: em um primeiro momento as crianças deitavam em decúbito ventral, no centro do banco; quando o estagiário batia uma palma, estas começavam a remar; quando o estagiário batia novamente a palma, deveriam sentar na prancha; na terceira palma deveriam voltar a remar porque estava vindo a onda; quando fossem duas palmas na sequência, deveriam ficar de pé na posição lateral, igual ao caranguejo.

Para promover o contato com o skate e os equipamentos de segurança, foram elencados três momentos, sendo estes trabalhados de forma progressiva. No primeiro momento, uma criança de cada vez, segurava na mão do estagiário para se deslocar com o skate. No segundo momento foi solicitado que a criança segurasse na ponta de uma corda e o estagiário na outra para puxar a criança com o skate; para as crianças que estavam se sentindo mais confiantes, foi proposto que, após iniciar o deslocamento com o auxílio do estagiário, elas poderiam largar a corda e continuar sozinhas. No terceiro e último momento foram entregues alguns skates para as crianças brincarem livremente da forma desejada, porém sempre com o estagiário supervisionando, a fim de evitar acidentes.

A dimensão atitudinal novamente se pautou, principalmente, nas questões de segurança, trabalhando elementos como: no surfe, a importância em utilizar roupas mais leves e protetor solar, devido à exposição ao sol, bem como a utilização de cordinha (leash), 
garantindo, assim, a união da prancha ao tornozelo para facilitar a retomada sobre a mesma após as quedas; por sua vez, no skate, a importância de utilizar os equipamentos de segurança próprios da modalidade (joelheiras, capacete, luvas, cotoveleiras e roupas mais resistentes para proteção de ralados). O uso dos cartões coloridos se manteve, confirmando ser uma estratégia bem-sucedida.

Ao desenvolverem uma experiência nas aulas de Educação Física na Educação Infantil, Costa Neto, Santos e Edney (2008), constataram que as práticas corporais de aventura desafiaram as crianças, fazendo com que o fato de conseguirem realizar as proporcionaram sentimentos de superação e elevação da autoestima. Semelhante a estes achados, pudemos perceber, durante o desenvolvimento das modalidades surfe e skate, confiança perante a ajuda do estagiário, bem como superação de limites e satisfação ao conseguir se deslocar no skate.

Ademais, a vivência do surfe potencializou a problematização de questões ambientais e a sensibilização das crianças para a importância da conservação do ambiente e dos recursos naturais. De acordo com Paixão (2017), o segmento da aventura possui uma ligação direta com a natureza, tendo em vista que o ambiente natural é espaço para a realização de diversas modalidades deste contexto esportivo, suscitando uma interação entre o praticante e o respectivo meio. Nesse sentido, destaca-se a articulação desta proposta com um projeto desenvolvido pela professora de Educação Física da instituição em que as crianças foram estimuladas a pensar em formas de reaproveitar a água, utilizada em uma das aulas que teve como tema a segurança no mar. Após a vivência a água foi armazenada em um recipiente com capacidade de aproximadamente 100 litros e depois utilizada pelas crianças para regar as plantas e a horta da instituição, promovendo, assim, a consciência ecológica nas crianças e a valorização dos espaços verdes e do contato com a natureza para as práticas corporais de aventura.

\section{Considerações finais}

O presente relato descreveu uma experiência com as práticas corporais de aventura na Educação Física Infantil, com ênfase para o potencial educativo desta prática corporal nas suas diferentes dimensões: atitudinal, conceitual e procedimental. Por meio desta experiência, adquirimos e ampliados nossos saberes acerca do trato pedagógico do conteúdo das práticas corporais de aventura na Educação Infantil e apesar do espaço de tempo reduzido, foi possível proporcionar às crianças a vivência de novos conteúdos por meio das modalidades surfe, skate, 
escalada, rapel e parkour. Porém, se houvesse um maior número de intervenções, o aprendizado poderia ser ampliado e outros conteúdos que compõem esse conjunto de práticas poderiam ser desenvolvidos, tais como canoagem, acampamento, sandboard, trilhas, entre outros.

A estratégia utilizada para ministrar as aulas, baseada nas três dimensões do conteúdo, favoreceu um melhor planejamento, desenvolvimento das atividades e respectiva avaliação da prática pedagógica. Ressalta-se que foi desafiador planejar as atividades adequadas para a faixa etária com a qual trabalhamos durante o estágio. Contudo, ficou evidente a relação que as três dimensões dos conteúdos tem entre si. É impossível dissociar, por exemplo, aspectos da dimensão procedimental de questões da dimensão conceitual. Ao mesmo tempo em que o professor aborda determinado movimento com as crianças, ele poderá mencionar questões de segurança, fatores de risco e equipamentos utilizados para a prática de determinada modalidade. Do mesmo modo, o professor poderá apresentar um movimento e discutir com as crianças sobre os limites do próprio corpo, enfatizando a necessidade de se entender os riscos envolvidos nestas práticas ou, ainda, atitudes de respeito e cooperação entre os seus pares.

Outro aspecto importante dessa experiência diz respeito à necessidade de se abordar temas relacionados ao ambiente, no sentido de despertar a sensibilização ambiental e a conservação dos espaços em que as práticas corporais de aventura são praticadas. Também é relevante enfatizar a adequação dos conteúdos conforme a realidade da instituição e do contexto no qual as crianças vivem, podendo ser explorados temas que contribuam para a aproximação real das crianças, a exemplo do que foi proposto ao longo desse estágio com a modalidade surfe, considerando que as crianças moram em uma ilha cercada por inúmeras praias.

Embora considerado um fator limitante, a falta de recursos e equipamentos específicos para o desenvolvimento das modalidades não comprometeu a realização das aulas. Nesse sentido, identificamos que o emprego de algumas estratégias contribuiu para o êxito do processo, tais como a exibição de vídeos sobre aspectos históricos e de segurança de cada modalidade, a utilização de materiais simples e a adequação dos espaços da própria instituição, mantendo o objetivo principal de cada prática corporal de aventura proposta pelo estagiário, demonstrando, assim, que é viável desenvolver este conteúdo com os recursos disponíveis no ambiente escolar.

Concluímos, a partir da experiência relatada, que é possível e, porque não dizer, desejável, inserir as práticas corporais de aventura na Educação Infantil, como uma forma de inovar os conteúdos tradicionalmente abordados nas aulas de Educação Física, possibilitando às crianças conhecer e experimentar conteúdos diversificados de maneira atraente e prazerosa, 
despertando nelas o desejo de conhecer e praticar outras modalidades. Assim, esperamos que este relato de experiência sirva de motivação para que outros estagiários e professores tematizem tais práticas em suas aulas, não restringindo as vivências das crianças e jovens pela falta de materiais e/ou espaços específicos. Por fim, destacamos o valor desta experiência, sugerindo que, para além dos aspectos aqui explorados, outros temas relacionados à dimensão conceitual, atitudinal e procedimental dos conhecimentos sejam explorados nas aulas de Educação Física desde a Educação Infantil.

\section{REFERÊNCIAS}

ARMBRUST, I. Skate. In: BERNARDES, L. A. Atividades de aventura para profissionais de Educação Física. São Paulo: Phorte, 2013. p. 181-206.

BARROSO, A. L. R.; DARIDO, S. C. A pedagogia do esporte e as dimensões dos conteúdos: conceitual, procedimental e atitudinal. Revista da Educação Física/UEM, Maringá, v. 20, n. 2, p. 281-289, 2. trim. 2009.

COSTA NETO, J. V.; SANTOS, S.; EDNEY, F. M. M. O colégio Sion do Rio de Janeiro, reinventando os esportes de aventura nas aulas de Educação Física. In: CONGRESSO BRASILEIRO DE ATIVIDADES DE AVENTURA, 3., Santa Teresa, 2008. Anais... Santa Teresa: ESFA, 2008. p. 64-66.

DARIDO, S. C. Os conteúdos da Educação Física na escola. In: DARIDO, S. C.; RANGEL, I. A. C. Educação Física na escola: implicações para a prática pedagógica. Rio de Janeiro: Guanabara Koogan, 2005. p. 64-69.

ESPINOZA, K. F. et al. Atividades de aventura na educação infantil e as inteligências múltiplas. In: CONGRESSO BRASILEIRO DE ATIVIDADES DE AVENTURA, 4., Mucugê, 2009. Anais... Mucugê: FTC, 2009. p. 121-123.

FRANCO, L. C. P. Atividades físicas de aventura na escola: uma proposta pedagógica nas três dimensões do conteúdo. 2008. 136 f. Dissertação (Mestrado em Ciências da Motricidade) - Universidade Estadual Paulista, Campinas, 2008.

FRANCO, L. C. P., CAVASANI, R., DARIDO, S. C. Práticas corporais de aventura. In: GONZÁLEZ, F. J.; DARIDO, S. C.; OLIVEIRA, A. A. B. Lutas, capoeira e práticas corporais de aventura. Maringá: Eduem, 2014. p. 101-135. (Práticas corporais e a organização do conhecimento, v. 4).

INÁCIO, H. L. D. et al. Práticas corporais de aventura na escola: possibilidades e desafios reflexões para além da Base Comum Curricular. Motrivivência, Florianópolis, v. 28, n. 48, p. 168-187, set. 2016. 
MARINHO, 2013. Introdução aos estudos das atividades de aventura: características, concepções e conceitos. In: BERNARDES, L. A. Atividades de aventura para profissionais de Educação Física. São Paulo: Phorte, 2013. p. 23-38.

MARINHO, A.; INÁCIO, H. L. D. Educação física, meio ambiente e aventura: um percurso por vias instigantes. Revista Brasileira de Ciências do Esporte, Campinas, v. 28, n. 3, p. 5570, maio 2007.

MARTINS, P.C.; ANSELMO, M. L. O esporte radical e suas possibilidades na educação infantil: o relato de experiência em uma unidade educacional. Cadernos de Formação RBCE, Florianópolis, v. 6, n. 2, p. 60-68, set. 2015.

PAIXAO, J. A. Esporte de aventura como conteúdo possível nas aulas de educação física escolar. Motrivivência, Florianópolis, v. 29, n. 50, p. 170-182, maio 2017.

PEREIRA, D. W.; CARCERONI, D. S. A evolução da escalada esportiva indoor na Educação Física Escolar em quatro escolas da rede particular de ensino da grande São Paulo. In: CONGRESSO PAULISTA DE EDUCAÇÃO FÍSICA, 9., Jundiaí, 2005. Anais... Jundiaí: Fontoura, 2005.

PEREIRA. D. W.; ARMBRUST, I. Pedagogia da aventura: os esportes radicais, de aventura e de ação na escola. Jundiaí: Fontoura, 2010.

PIMENTEL, G. G. A. et al. Atividades alternativas na educação física escolar. Revista Educação Física UNIFAFIBE, Bebedouro, v. 5, p. 176-196, set. 2017.

SOUZA, F. A. SILVA, P. C. C. A escalada nas aulas de Educação Física escolar no ensino médio. Cadernos de Formação RBCE, Florianópolis, v. 4, n. 2, p. 44-54, set. 2013.

SOUZA, J. C. M. Surfe. In: BERNARDES, L. A. Atividades de aventura para profissionais de Educação Física. São Paulo: Phorte, 2013.p. 53-64.

TAHARA, A. K.; DARIDO, S. C. Práticas corporais de aventura em aulas de educação física na escola. Conexões, Campinas, v. 14, n. 2, p. 113-136, abr./jun., 2016.

UVINHA, R. R. Juventude, lazer e esportes radicais. São Paulo: Manole, 2001.

ZABALA, A. A prática educativa: como ensinar. Porto Alegre: Artmed, 1998. 


\section{SOBRE OS AUTORES:}

\section{Filipe Botelho Francisco}

Licenciado em Educação Física pelo Centro de Ciências da Saúde e do Esporte (CEFID) da Universidade do Estado de Santa Catarina (UDESC). Laboratório de Pesquisa em Práticas Pedagógicas da Educação Física (LAPRAPEF). E-mail: filipe-botelho1@ @otmail.com

(iD http://orcid.org/0000-0001-9338-4477

\section{Juliana de Paula Figueiredo}

Doutora em Educação Física pela Universidade Federal de Santa Catarina (UFSC). Mestre em Ciências da Motricidade pela Universidade Estadual Paulista Júlio de Mesquita Filho (UNESP). Laboratório de Pesquisa em Lazer e Atividade Física (LAPLAF). Laboratório de Estudos do Lazer (LEL). E-mail: julianapfig@ hotmail.com

iD http://orcid.org/0000-0001-8477-465X

\section{Viviane Preichardt Duek}

Doutora em Educação pela Universidade Federal do Rio Grande do Norte (UFRN). Professora Adjunta da Universidade do Estado de Santa Catarina (UDESC). Laboratório de Pesquisa em Práticas Pedagógicas da Educação Física (LAPRAPEF). E-mail: vividuek@ hotmail.com. iD http://orcid.org/0000-0002-0774-7495 